\title{
Similar patterns of patterns of community organization characterize distinct groups of different trophic levels in the plankton of the NW Mediterranean Sea
}

\author{
V. Raybaud ${ }^{1,2}$, A. Tunin-Ley ${ }^{1,3}$, M. E. Ritchie $^{4}$, and J. R. Dolan ${ }^{1,3}$ \\ ${ }^{1}$ UPMC Univ Paris 6, UMR 7093, Laboratoire d'Océanographie de Villefranche, Observatoire Océanologique de \\ Villefranche-sur-Mer, Station Zoologique, B.P. 28, 06230 Villefranche-Sur-Mer, France \\ ${ }^{2}$ CNRS, UMR 7093, Laboratoire d'Océanographie de Villefranche, Observatoire Océanologique de Villefranche-sur-Mer, \\ Station Zoologique, B.P. 28, 06230 Villefranche-Sur-Mer, France \\ ${ }^{3}$ CNRS, UMR 7093, Laboratoire d'Océanographie de Villefranche, Microbial Ecology and Biogeochemistry, Observatoire \\ Océanologique de Villefranche-sur-Mer, Station Zoologique, B.P. 28, 06230 Villefranche-Sur-Mer, France \\ ${ }^{4}$ Biology Department, Syracuse University, Syracuse, NY, USA
}

Received: 24 September 2008 - Published in Biogeosciences Discuss.: 12 December 2008

Revised: 27 February 2009 - Accepted: 5 March 2009 - Published: 18 March 2009

\begin{abstract}
Planktonic populations were sampled over a 4 week period in the NW Mediterranean, at a site subject to little vertical advection during the Dynaproc 2 cruise in 2004. The characteristics of the phytoplankton, the tintinnid community and the zooplankton have recently been described in detail. Based on these studies, we compared the characteristics of 3 well-circumscribed assemblages of different trophic levels: Ceratium of the phytoplankton, herbivorous tintinnids of the microzooplankton, and large $(>500 \mu \mathrm{m})$ omnivorous and carnivorous copepods of the metazoan zooplankton. In all three groups, diversity as H' or species richness, was less variable than concentration of organisms. Plotting time against species accumulation, the curves approached plateau values for Ceratium spp, tintinnids and large copepods but only a small number of species were consistently present (core species) and these accounted for most of the populations. For Ceratium core species numbered 10, for tintinnids 11 species, and for large copepods, core species numbered 4 during the day and 16 at night. Ceratium, tintinnids and large copepods showed some similar patterns of community structure in terms of species abundance distributions. Ceratium species were distributed in a log-normal pattern. Tintinnid species showed a log-series distribution. Large copepod assemblages were highly dominated with night samples showing much higher abundances and greater species richness than day samples. However, species abundance distributions were similar between day and night and were mostly log-
\end{abstract}

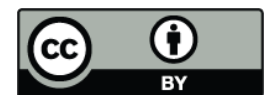

Correspondence to: J. Dolan

(dolan@obs-vlfr.fr) normal. The paradox of the plankton, describing phytoplankton communities as super-saturated with species, extends to the microzooplankton and zooplankton.

\section{Introduction}

Many groups of planktonic organisms are characterized by high species-richness. Hutchinson (1961) was the first to formally state that there appears to be an unreasonable number of phytoplankton species for an apparently homogenous environment- "the paradox of the plankton". The paradox of a supersaturation of species has been extended beyond phytoplankton to that of a general feature of aquatic systems (Roelke and Eldridge, 2008). Over the years many solutions to the paradox, most applicable only to phytoplankton, have been proposed but none have found general acceptance (Roy and Chattopadhyay, 2007). The answer may lie in examining mechanisms or phenomena which impact planktonic organisms in general. This possibility is difficult to evaluate as a single distinct taxonomic or trophic group is nearly always examined in isolation.

There have been a few studies comparing the large, very heterogeneous groups of "phytoplankton" and "zooplankton". Interestingly, "phytoplankton" and "zooplankton" appear to show distinct differences. For example, in lakes phytoplankton and zooplankton display different species abundance distributions (Walker and Cyr, 2007). However, the phytoplankton and zooplankton were not sampled in the same lakes. In the marine plankton, phytoplankton diversity

Published by Copernicus Publications on behalf of the European Geosciences Union. 
is a hump-shaped function of biomass along a large spatial gradient while zooplankton diversity appears to be a nearlinear function of biomass (Irigoen et al., 2004). However, averaged over large time scales (decades) in a single large system - the Eastern North Pacific Gyre, zooplankton and phytoplankton show very similar species abundance distributions (McGowan and Walker, 1993). Phytoplankton and zooplankton diversity responds distinctly to disturbances, such as flushing, based on the results of experiments with lake plankton (Flöder and Sommer, 1999) and estuarine plankton (Buyakates and Roelke, 2005). Thus, frustratingly few generalities about differences or similarities in plankton community structure have emerged, perhaps because both phytoplankton and zooplankton are heterogeneous groups, and phytoplankton are much more abundant and often more diverse than zooplankton.

Here we take a different approach to comparing phytoplankton and zooplankton, that of examining the diversity and community structure of circumscribed groups of species within the more general trophic classes of plankton. We profit from the simultaneous in-depth studies of phytoplankton (Lasternas et al., 2008), zooplankton (Raybaud et al., 2008) and microzooplankton (Dolan et al., 2009) conducted during the program "DYNAPROC 2". We selected the large, generally omnivorous and carnivorous ( $>500 \mu \mathrm{m})$ copepods, Ceratium dinoflagellates of the phytoplankton, and herbivorous tintinnid ciliates, to compare the characteristics of zooplankton, phytoplankton and microzooplankton. Each group is well-circumscribed, species-rich and one in which species identifications are straightforward. Sampling details, taxonomic identification, and sample sizes for each of the 3 assemblages appear as 3 independent papers (Dolan et al., 2009; Lasternas et al., 2008; Raybaud et al., 2009). All 3 groups were treated by workers considered as experts, with regard to taxonomy as well as sampling, in their respective fields. Taxonomic skills employed in examining the 3 groups can be considered as expert and as the best available.

Other than the planktonic existence, the assemblages have little in common. To begin with, the groups are trophically distinct. Ceratium species are dinoflagellate primary producers, containing chloroplasts. Tintinnids are ciliates, part of the herbivorous microzooplankton and feed mainly on small phytoplankton (5-25 $\mu \mathrm{m}$ in size). The large copepods (e.g. Neocalanus) are generally assumed to be omnivorous or carnivorous. The three sets of species vary in generation times with that of large copepods measured in weeks or months, Ceratium spp in days, and tintinnids in hours. The 3 groups also represent different degrees of phylogenetic cohesion: Ceratium are all obviously in a single genus; tintinnids represent a ciliate sub-order and "large copepods" groups species of distinct orders. The large copepod community differs as well from Ceratium and tintinnids in that day and night communities in the surface layers are distinct with nighttime copepod communities constituted mainly of migrating taxa found in deeper waters during the day.
The three assemblages, whilst of distinct trophic levels, are unlikely to have direct impact on one another. The large copepods feed on Ceratium and tintinnid-size prey items but are not found in concentrations sufficient to affect Ceratium spp. or tintinnids, given typical feeding rates for large copepods. This consideration is based on the observations that the filtration rates of large copepods is roughly $500 \mathrm{ml}$ per day (Dagg et al., 2006), multiplied by the concentrations of large copepods, typically 10's per cubic meter, yields an estimate of daily "large copepod community grazing" which is less than $0.3 \%$ of the surface layer or of the habitat of Ceratium and tintinnids. With regard to the possible interactions between Ceratium and tintinnids, Ceratium spp., most of which exceed $100 \mu \mathrm{m}$, are too large to be ingested by most tintinnids. Based on data from laboratory experiments, the maximum size of tintinnid food items is about one half of the lorica oral diameter and the size of prey items most efficiently exploited are of a size equal to $1 / 4$ the oral diameter (Dolan et al., 2002). As the smallest Ceratium species is about 100 microns, and most tintinnids have an oral diameter of 30-40 microns, it is unlikely that tintinnids feed on Ceratium. Furthermore, there are no reports of tintinnids consumming Ceratium.

Here we compare the community characteristics of these sets to organisms in terms of the stability of species and the structure of community composition by examining species abundance distributions and compare the short-term relative variabilities. We do not attempt to compare absolute values of diversity indexes or species-richness but rather focus on the overall general characteristics and relative variability of the 3 assemblages.

\section{Material and method}

\section{$2.1 \quad$ Sampling}

The Dynaproc 2 cruise, in September-October 2004, permitted repeated sampling over a 4 week period at a site in the NW Mediterranean Sea characterized by little vertical advection. Detailed descriptions of the study site and sampling appear elsewhere; here we will briefly review methods used to study copepods (Raybaud et al., 2008), phytoplankton (Lasternas et al., 2008) and tintinnid ciliates (Dolan et al., 2008). The copepod data considered here are derived from the samples collected using a $500 \mu \mathrm{m}$ mesh net BIONESS apparatus. Complete details of details of the sampling regime, species compositions and data on organisms other than large copepods are given in Raybaud et al. (2008). The BIONESS device samples discrete depth strata in the water column. Here only data from samples collected between 0 and $100 \mathrm{~m}$ are considered; alternating day and night samples were obtained. A total of 7 day samples were analyzed, with an average of 705 large copepods per sample, and 7 night samples, with an average of 4243 individuals per sample. 
Complete details of the microphytoplankton sampling and data are given in Lasternas et al. (2008). Ceratium data considered here are derived from samples obtained using a $53 \mu \mathrm{m}$ mesh phytoplankton net drawn from $90 \mathrm{~m}$ to the surface. Here, we analyzed only data on recognized species of Ceratium, pooling "strains". Samples were obtained on 17 dates; a minimum of 150 individual Ceratium were examined in each sample. Tintinnid sampling and sample analysis are presented in detail in Dolan et al. (2008). Samples were obtained using Niskin water bottles from 6 depths between the surface and $90 \mathrm{~m}$ on 18 dates. Approximately 1000 tintinnnids were enumerated for each date.

\subsection{Data analysis}

Species accumulation curves of large copepods, Ceratium and tintinnids were plotted as cumulative numbers of species against time. Taxonomic diversity was estimated for each date for each group as the Shannon index (ln-based, e.g., Magurran, 2004) and species richness. For each species, we plotted overall abundance against frequency of detection as $\%$ presence out of total sampling dates. We distinguished two sets of species: core species, defined as those present on each of the sampling dates and occasional species, defined as not detected on one or more dates. For copepods, Ceratium and tintinnids, we constructed log-rank abundance curves for each date by calculating relative abundance for each species and ranking species from highest to lowest and plotting $\ln$ (relative abundance) vs. rank. Then, for each entire assemblage as well as separately for the core and occasional species (except for copepods which had an insufficient number of occasional species), we constructed hypothetical log-rank abundance curves that could fit the data by using parameters of the particular assemblage. A total of six dates were chosen for Ceratium, 4 day samples and 4 night samples for the large copepods to compare with the recent analysis of the tintinnid assemblages (i.e., Dolan et al., 2009). We constructed curves for three different popular models of community organization: geometric series, log-series, and log-normal, as in Dolan et al. $(2007,2009)$ and summarized below.

A geometric series distribution represents the result of the priority exploitation of resources by species arriving sequentially in a community (Whittaker, 1972), and is modeled by assuming that each species' abundance is proportional to a fixed proportion $p$ of remaining resources. Thus the relative abundance of the $i$ th species is $(1-p) p^{i-1}$. For each assemblage, we used the relative abundance of the most abundant species on the date of interest to estimate $p$.

A log-series distribution represents the result of random dispersal from a larger community, a metacommunity in Hubbell's neutral theory (Hubbell, 2001). In a community exhibiting a log-series distribution, species having abundance $n$ occur with frequency $\alpha x^{n} / n$, where $x$ is a fitted parameter and $\alpha$ is Fisher's alpha, a measure of species diver- sity that is independent of total community abundance. For a given community with $N$ total individuals and $S$ species, $x$ can be found (Magurran, 2004) by iteratively solving the following equation for $x$ : $S / N=-\ln (1-x)(1-x) / x$ and then finding Fisher's alpha as $\alpha=N(1-x) / x$. In the case of copepods, Ceratium and tinntinnid communities, we employed the observed $S$ and $N$ of the given date to calculate $x$ and $\alpha$.

A log-normal species abundance distribution is thought to result from either a large number of species of independent population dynamics with randomly varying (in either space or time) exponential growth, such that $N(i) \propto \mathrm{e}^{r i}$ where $r_{i}$ is a random variable. Since $N(i)$ is a function of an exponential variable, $\ln (N(i))$ should be normally distributed (May 1975). Alternatively, species in a community that are limited by multiple factors that act on population size in a multiplicative fashion should also exhibit a log-normal distribution of abundances. We calculated the expected log-normal species abundance distribution for each tintinnid sample by calculating the mean and standard deviation of $\ln$ (abundance) and using these parameters to generate expected abundance distributions for the $S$ species in the sample in a spreadsheet. We then calculated the mean abundance for each species, ranked from highest to lowest, and then calculated relative abundance.

For selected dates, the observed rank abundance distributions for the 3 sets of species were compared to the hypothetical models using a Bayesian approach: an Akaike Goodness of fit calculation (Burnham and Anderson, 2004). Using this approach, an Akaike Information Criterion (AIC) was determined as the natural logarithm of the mean (sum divided by $S$ ) of squared deviations between observed and predicted $\ln ($ relative abundance) for all ranked $S$ species plus an additional term to correct for the number of estimated parameters, $k$ ( 1 for geometric series and 2 each for log-series and log-normal distributions): $(S+k) /(S-\mathrm{k}-2)$. The lower the calculated AIC value, the better the fit. A difference of 1 in AIC corresponds roughly to a three-fold difference in fit, so this parameter is sensitive enough for our data to judge the fit of the three different models.

\section{Results}

\subsection{Temporal trends}

Throughout the sampling period the three groups of organisms varied considerably in concentration, that is, by factors of 3 to 5, and independently as well (Fig. 1). Ceratium ranged from about 800 to nearly 4000 cells $\mathrm{m}^{-3}$. Tintinnid concentrations varied from 8000 to 48000 cells m$^{-3}$. Large copepods were found in concentrations ranging from 1.7 to 4.5 individuals per $\mathrm{m}^{3}$ in the day samples and 10 to 55 individuals $\mathrm{m}^{-3}$ in the night samples. Compared to the shifts in concentrations, all 3 groups exhibited a relative stability in diversity, estimated as either species richness or the Shannon index. 

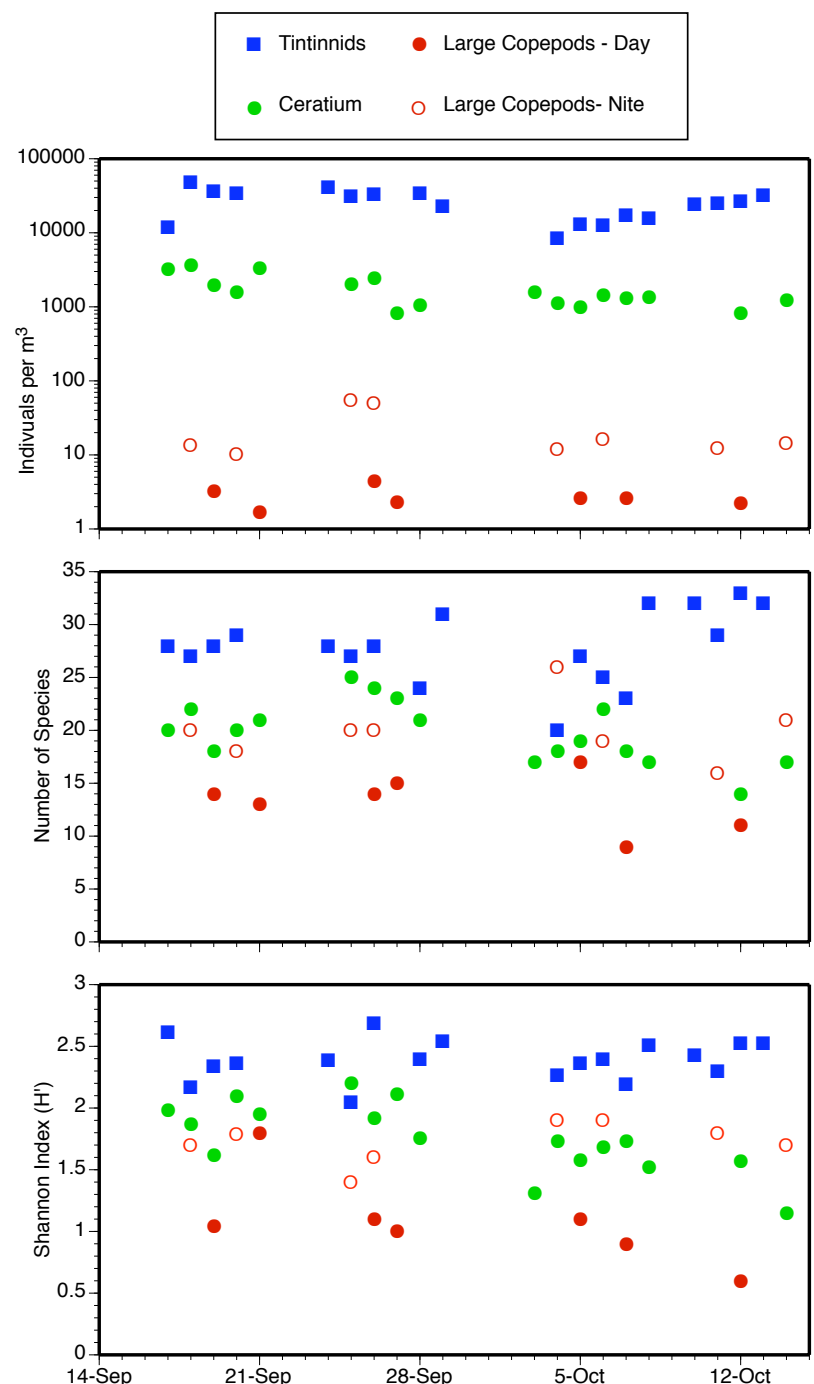

Fig. 1. Temporal changes in the concentrations (top panel), species richness (middle panel) and Shannon Index of diversity (bottom panel) of Ceratium, tintinnids and copepods.

The number of Ceratium species encountered each day varied between 14 and 24; tintinnids species numbered from 20 to 33. The copepod communities sampled in the daytime consisted of 9 to 15 species while the night samples contained 19 to 26 species. Thus, for all three groups of organisms, maximum and minimum species richness differed by about a factor of about 1.5. Similarly, the Shannon index metric of diversity for each group varied in a relatively narrow range compared to organismal concentrations. The Shannon metric $\left(H^{\prime}\right)$ ranged between 1.3 and 2.1 for $\mathrm{Cer}$ atium, and from 2.0-2.7 for tintinnids. For the copepods sampled during the day, $\mathrm{H}^{\prime}$ varied between 0.6 and 1.8 and values for night communities ranged from 1.4 to 1.9.
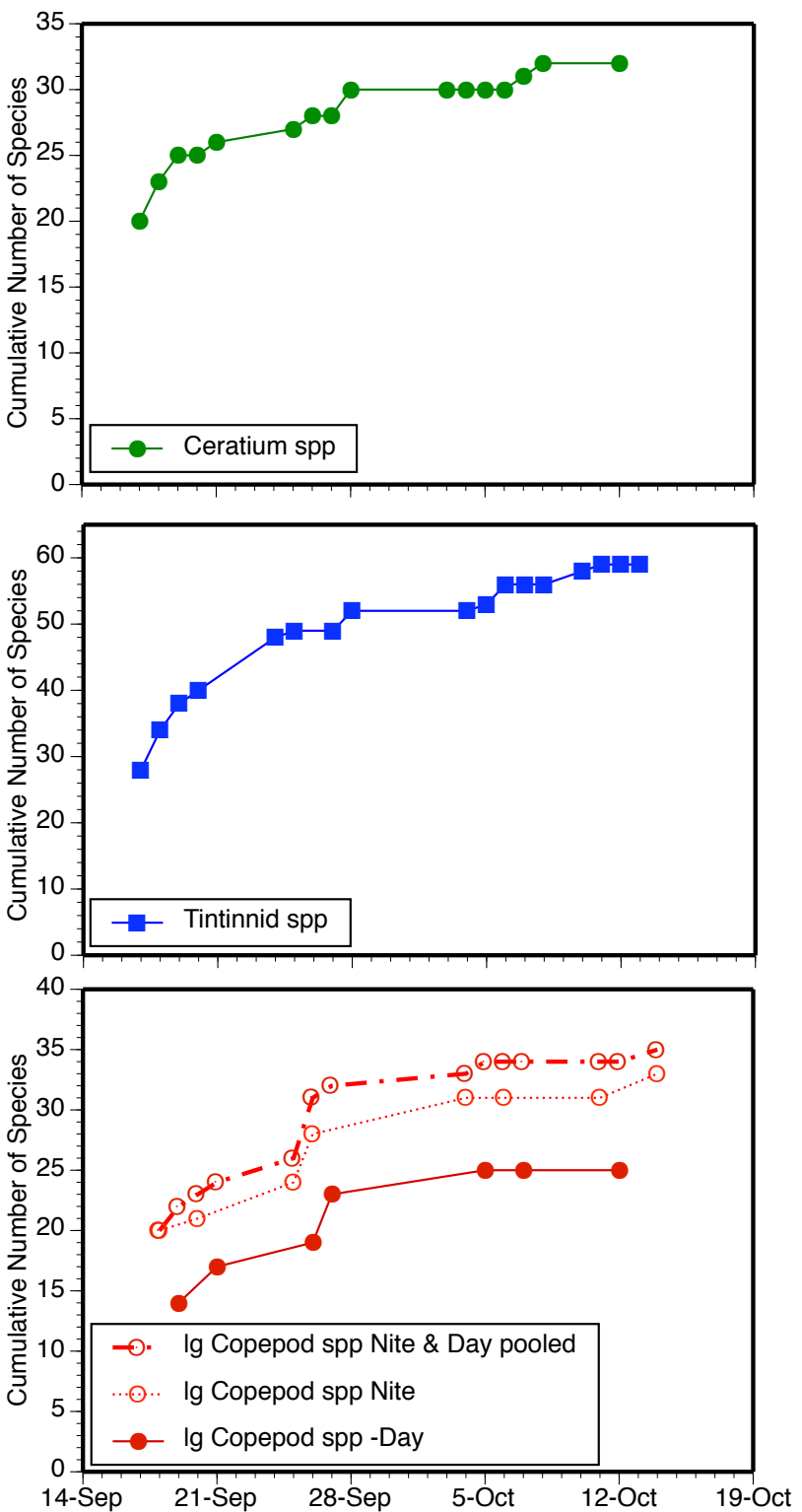

Fig. 2. Species accumulation with time for Ceratium (top panel), tintinnids (middle panel), and copepods (bottom panel).

\subsection{Species pools}

For each of the three groups, curves of species accumulation with time showed near linear increases of species with time over the first 10 sampling dates and began to plateau at the end of the sampling period (Fig. 2). The species pool encountered for Ceratium numbered 32 and that for tintinnids 59. Day samples yielded a total of 25 species of large copepods, night samples contained 34 species and pooling both night and day, a total of 35 species of large copepods. For Ceratium, tintinnids and large copepods, sampling over a 4 week long sampling period revealed the presence of about 1.5 times the number of species found in the first sample. 

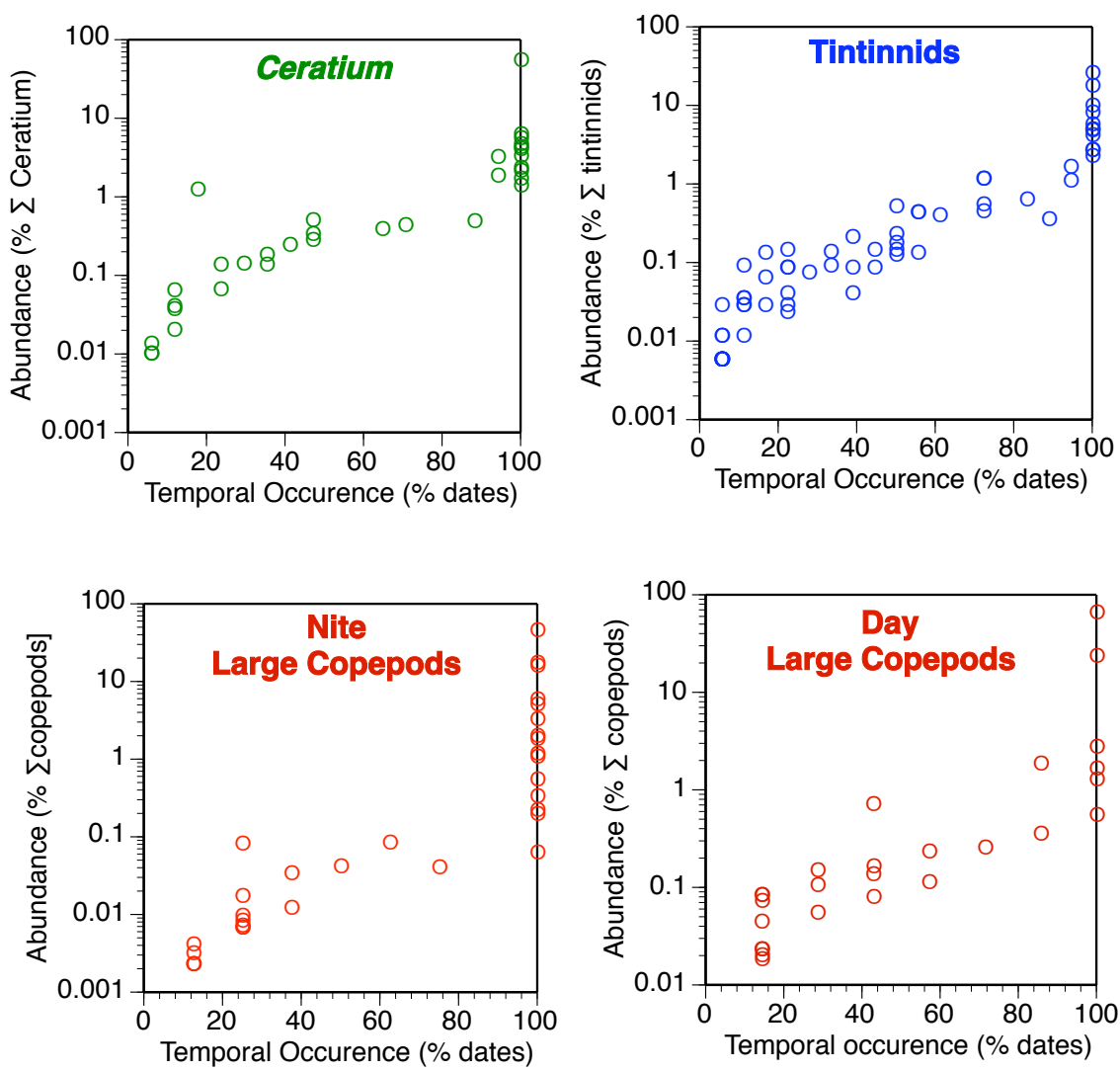

Fig. 3. Relationships between the overall (all samples pooled) relative abundance of species and their temporal occurrence in Ceratium (top left), tintinnids (top right), nite time copepods (bottom left) and day time copepods (bottom right).

Within each group, the presence of a given species over the 4 week sampling period was related to its total overall abundance (Fig. 3). For all groups there was a relatively small number of species, compared to the total species pool, which accounted for the majority of the population. These species - the core species - were consistently present in all samples as against the much larger number of "occasional" species. Core species of Ceratium and tintinnids numbered 11 each; for large copepods such species numbered 6 during the day and 15 at night. The numbers of occasional species of $\mathrm{Cer}$ atium, tintinnids and large copepods were 21, 48 and 19, respectively. For all the groups there was then a relatively small number of species, compared to the total species pool which accounted for the majority of the population and were consistently found - the core species and a far larger number of "occasional" species.

\subsection{Species abundance distributions}

Examples of species abundance distributions are shown in Fig. 4. Typically, the 5 most abundant species accounted for about $80 \%$ of the total individuals in all three groups. Comparison of observed species abundance distributions with modeled distributions showed that the geometric model was

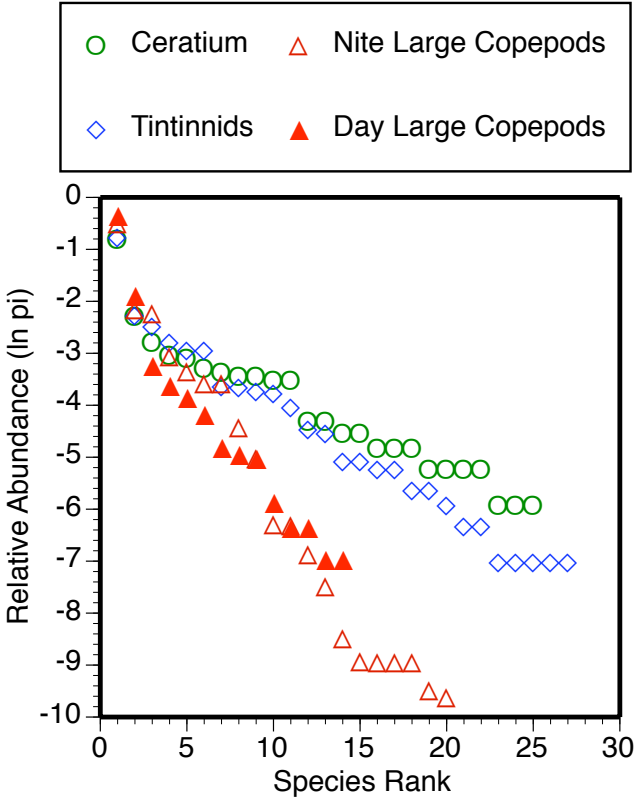

Fig. 4. Typical species abundance distributions. 
Table 1. Results of the analysis of the Ceratium species abundance distributions. For each date the observed log-rank abundance curve was compared to model-derived log-normal, geometric and log-series curves using an Akaike Information Criterion test. The values in boldface denote the lowest AIC value, indicating the closest fit. A difference of 1 AIC unit is equal to about a 3-fold difference in closeness of fit. Log-normal distributions followed by log-series provided the closest fit to observed distributions.

\begin{tabular}{lrrrr}
\hline \multicolumn{5}{c}{ Ceratium } \\
\hline DATE & \# Spp & log-normal & geometric & log-series \\
18 Sept & 22 & $\mathbf{- 0 . 2 3}$ & 4.71 & 0.55 \\
20 Sept & 20 & $-\mathbf{0 . 2 7}$ & 3.87 & -0.15 \\
25 Sept & 25 & $-\mathbf{1 . 0 6}$ & 4.46 & 0.85 \\
26 Sept & 24 & $\mathbf{- 0 . 4 7}$ & 4.26 & 0.53 \\
4 Oct & 18 & $\mathbf{- 0 . 3 4}$ & 4.61 & 0.15 \\
6 Oct & 23 & $\mathbf{0 . 5 8}$ & 5.14 & 0.84 \\
\hline
\end{tabular}

the poorest fit for all three groups. The Ceratium species abundance distributions were most often best fit by a lognormal distribution (Table 1) while those for tintinnids were most often best fit by a log-series model (Table 2). Copepod species abundance distributions were variable in both day and night populations but were overall most often bestfit by a log-normal distribution (Table 3). The goodness of fit for Ceratium and tintinnids to their respective best fit statistical model provided was much stronger (lower AIC) than for copepods (compare Tables 1-3). However, for all the groups, AIC values estimator of fit for the log-normal and log-series fits were often similar.

\section{Discussion}

We wished to establish if there are general characteristics describing assemblages of marine planktonic organisms. We compared distinct groups of species, each investigated separately by sampling the same planktonic community repeatedly over a 4 week period (Lasternas et al., 2008; Dolan et al., 2009; Raybaud et al., 2009). The groups belong to different trophic levels, found in different concentrations, and have different generation times. To our knowledge, no previous study has exploited data derived from intensive sampling of multiple trophic levels in the plankton. We examined the characteristics of the assemblages and assessed temporal variability.

We found a great deal of similarity between Ceratium spp., tintinnids and large copepods (including the different day and night copepod populations). All 3 groups displayed a relative temporal stability of diversity, measured as species richness
Table 2. Results of the analysis of the tintinnid species abundance distributions. For each date the observed log-rank abundance curve was compared to model-derived log-normal, geometric and logseries curves using an Akaike Information Criterion test. The values in boldface denote the lowest AIC value, indicating the closest fit. A difference of 1 AIC unit is equal to about a 3-fold difference in closeness of fit. Log-series distributions followed by log-normal provided the closest fit to observed distributions.

\begin{tabular}{lrrrr}
\hline \multicolumn{5}{c}{ Tintinnids } \\
\hline DATE & \# Spp & log-normal & geometric & log-series \\
19 Sept & 28 & 3.88 & 1.71 & $-\mathbf{0 . 3 8}$ \\
20 Sept & 29 & 3.80 & 1.30 & $-\mathbf{0 . 7 0}$ \\
25 Sept & 27 & -0.50 & 4.59 & $\mathbf{- 0 . 8 0}$ \\
26 Sept & 27 & -0.11 & 2.86 & $\mathbf{- 0 . 8 3}$ \\
4 Oct & 20 & 0.11 & -0.38 & $\mathbf{- 0 . 4 5}$ \\
6 Oct & 25 & -0.75 & 1.28 & $\mathbf{- 1 . 1 2}$ \\
\hline
\end{tabular}

or H', despite large changes in concentrations. In each group, only a small fraction of the total species found were present consistently and these "core species" accounted for most of the individuals. For all three groups, the species accumulation curves approached saturation but did not reach a plateau. The species abundance distributions, based on comparisons with modeled distributions, were log-normal or log-series and the 2 distributions were often difficult to distinguish. For example, in a previous study of the community structure of the tintinnid community, the log-series pattern of the entire community was shown to be a combination of the log-normal pattern of the core species alone and the log-series pattern of the occasional tintinnid species (Dolan et al., 2009).

Our findings of several common characteristics in planktonic groups based on comparing Ceratium, tintinnids and large copepods contrast with some other findings based on different scales of time and space, or different hierarchical groupings. For example, within the phytoplankton Peuyo (2006) compared "dinoflagellates" and "diatoms" collected from several sites in the Mediterranean and in coastal water of Venezuela. Peuyo described distinct species abundance distributions for the two taxonomic groups of phytoplankton: log-normal for dinoflagellates and log-series for diatoms. The two distributions are thought to characterize different community structures. For the diatoms, the logseries distribution follows from neutral models of biodiversity and suggests near ecological equivalence among species (Etienne and Alonso, 2007).

In comparing lake zooplankton and phytoplankton and fish, Walker and Cyr (2007) concluded that zooplankton and fish showed a log-series distribution, which differed from that of phytoplankton in that species abundance distributions 
Table 3. Results of the analysis of the large copepod species abundance distributions. For each date the observed log-rank abundance curve was compared to model-derived log-normal, geometric and log-series curves using an Akaike Information Criterion test. The values in boldface denote the lowest AIC value, indicating the closest fit. A difference of 1 AIC unit is equal to about a 3-fold difference in closeness of fit. Both day and night populations showed distributions which varied between log-normal and log-series based on the closest fit to observed distributions.

\begin{tabular}{lrrrrrrrr}
\hline & $\begin{array}{r}\text { Copepod } \\
\text { Day }\end{array}$ & & & \multicolumn{5}{c}{ Copepod } \\
Night \\
\hline Date & \#spp & normal & geom & series & \# spp & normal & geom & series \\
18 Sept & 20 & $-\mathbf{0 . 7 3}$ & -0.15 & 1.78 & 20 & 0.98 & $-\mathbf{0 . 1 5}$ & 0.978 \\
20 Sept & 15 & 0.27 & 0.82 & $-\mathbf{0 . 9 4}$ & 18 & $\mathbf{0 . 5 6}$ & 0.68 & 1.81 \\
25 Sept & 14 & 0.23 & 3.56 & $-\mathbf{0 . 2 1}$ & 20 & $\mathbf{0 . 2 3}$ & 3.21 & 1.10 \\
4 Oct & 14 & $\mathbf{0 . 3 5}$ & 1.82 & 1.89 & 26 & 0.04 & 3.23 & $-\mathbf{0 . 3 7}$ \\
\hline
\end{tabular}

of phytoplankton did not show the log-series distribution, in apparent contrast to marine diatoms (Peuyo, 2006). These studies however, differed from ours in that the groups compared were not intensively sampled, nor were some in the same system. Hence, it is not unreasonable to suppose that our findings of similarity among different trophic levels in the plankton maybe be extended to other systems because at present there is no adequate comparative data suggesting the contrary. There may be larger differences between systems than within systems. For example considering "zooplankton" alone, in lakes the latitudinal differences in diversity are positively related to stability (Shurin et al., 2007), a pattern the phytoplankton might follow as well. With regard to only species abundance distributions, there is at present little enough data comparing distinct trophic levels that this lacuna has been listed recently among the "top dozen directions" to pursue in "species abundance research" research (McGill et al., 2007).

Here we have examined and considered only temporal variability. A question which may arise is that of spatial variability. In this regard it is perhaps worth noting that separate studies of Ceratium (Weiler, 1980) and tintinnid (Dolan et al., 2007) community structure across the subtropical Pacific reached similar conclusions concerning the remarkable consistency of species abundance patterns across very large spatial scales. Unfortunately, no similar examination of spatial variability in the community structure of large copepods has been conducted, to our knowledge.

For all three groups, a minority of species, core species, accounted for a large majority of the individuals. Sampled over a 4 week period, the species accumulation curve of each group approached, but did not reach a plateau, suggesting that continued sampling would have yielded additional species of Ceratium, tintinnids and copepods. It appears that each assemblage could be characterised as being constituted of a large number of transient species, or forms present in near trace concentrations. The ecological implications of such a pattern is the possibility that a common characteristic of each assemblage is the presence of a large pool of under-study species, present to fill a niche should it become available, thereby contributing to the long-term stability of each assemblage.

\section{Conclusions}

We conclude then that within the NW Mediterranean Sea, the characteristics of Ceratium species of the phytoplankton (high species richness coupled with a stable dominance of a few forms) also characterizes assemblages from the consumer trophic levels, the tintinnid ciliates as well as large copepods. This convergence in proportion of consistently present species, large species pools and low variability in diversity suggests that, despite their trophic differences, body size and generation time, similar, general mechanisms, such as resource pre-emption coupled with local dispersal limitation, for example, may structure their communities (Magurran and Anderson, 2003). However, we found important and consistent differences in species abundance distributions between Ceratium phytoplankton and large copepods, which exhibited mostly log-normal distributions, and tintinnids, which exhibited mostly log-series. We find no clear explanation for this difference. However, because we compared communities from the same intensive samples in the same body of water, differences in abundance distributions may be more likely to arise from ecological differences among the different trophic levels than from environmental differences that have plagued previous comparative studies.

Acknowledgements. Support for this work was provided by the ANR-Biodiversity program and the Pôle-Mer PACA through the AQUAPARADOX project.

Edited by: S. W. A. Naqvi 


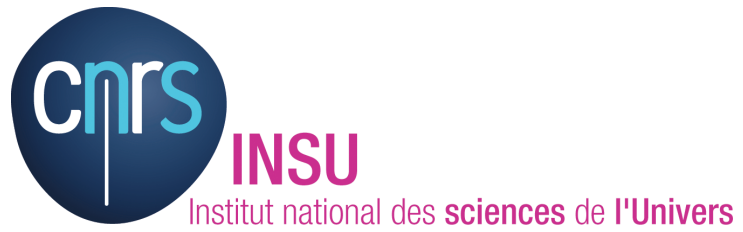

The publication of this article is financed by CNRS-INSU.

\section{References}

Burnham K. P. and Anderson, D. R.: Model selection and multimodel inference: a practical information-theoretic approach, Springer, New York, 496 pp., 2002.

Buyakates, Y. and Roelke, D.: Influence of pulsed inflows and nutrient loading on zooplankton and phytoplankton community structure and biomass in microcosm experiments using estuarine assemblages, Hydrobiologia, 548, 233-249, 2005.

Dagg, M. J., Liu, H., and Thomas, A. C.: Effects of mesoscale phytoplankton variability on the copepods Neocalanus flemingeri and N. plumchrus in the coastal Gulf of Alaska, Deep-Sea Res. II, 53, 321-332, 2006.

Dolan J. R., Claustre, H., Carlotti, F., Plounevez, S., and Moutin, T.: Microzooplankton diversity: relationships of tintinnid ciliates with resources, competitors and predators from the Atlantic Coast of Morocco to the Eastern Mediterranean, Deep-Sea Res. I, 49, 1217-1232, 2002.

Dolan, J. R., Ritchie, M. R., and Ras, J. :The "neutral" community structure of planktonic herbivores, tintinnid ciliates of the microzooplankton, across the SE Tropical Pacific Ocean, Biogeosciences, 4, 297-310, 2007, http://www.biogeosciences.net/4/297/2007/.

Dolan, J. R., Ritchie, M. E., Tunin-Ley, A., and Pizay, M.-D.: Dynamics of core and occasional species in the marine plankton: tintinnid ciliates in the north-west Mediterranean Sea, J. Biogeogr., in press, 2009.

Etienne, R. S. and Alonso, D.: Neutral community theory: how stochasticty and dispersal-limitation can explain species coexistence, J. Stat. Physics, 128, 485-510, 2007.

Flöder, S. and Sommer, U.: Diversity in planktonic communities: an experimental test of the intermediate disturbance hypothesis, Limnol. Oceanogr., 44, 1114-1119, 1999.

Hubbell, S. R.: The unified neutral theory of biodiversity and biogeography, Princeton University Press, Princeton, NJ, USA, 375 pp., 2001.

Hutchinson, G. E.: The paradox of the plankton, Am. Nat., 95, 137145, 1961

Irigoien, X., Huisman, J., and Harris, R. P: Global biodiversity patterns of marine phytoplankton and zooplankton, Nature, 429, 863-867, 2004.
Lasternas, S., Tunin-Ley, A., Ibañez, F., Andersen, V., Pizay, M.-D., and Lemée, R.: Dynamics of microphytoplankton abundance and diversity in NW Mediterranean Sea during late summer condition (DYNAPROC 2 cruise; September-October 2004), Biogeosciences Discuss., 5, 5163-5202, 2008, http://www.biogeosciences-discuss.net/5/5163/2008/.

Magurran, A. E.:Measuring biological diversity, Blackwell Publishing, Oxford, 256 pp., 2004.

Magurran, A. E. and Henderson, P. A.: Explaining the excess of rare species in natural species abundance distributions, Nature, 422, 714-716, 2003.

May, R. M.: Patterns of species abundance and diversity, in: Ecology and evolution of communities, edited by: Cody, M. L. and Diamond, J. M., Harvard University Press, Boston, 81-120, 1975.

McGill, B. J., Etienne, R. S, Gray, J. S., et al.: Species abundance distributions: moving beyond single prediction theories to integration within an ecological framework, Ecol. Lett., 10, 9951015, 2007.

McGowan, J. A. and Walker, P. W.: Pelagic diversity patterns, in: Species diversity in ecological communities: historical and geographical perspectives, edited by: Ricklefs, R. E. and Schluter, D., Chicago, USA, University of Chicago Press, 203-214, 1993.

Peuyo, S. : Diversity: between neutrality and structure, Oikos, 112, 392-405, 2006.

Raybaud, V., Nival, P., Mousseau, L., Gubanova, A., Altukhov, D., Khvorov, S., Ibañez, F., and Andersen, V.: Short term changes in zooplankton community during the summer-autumn transition in the open NW Mediterranean Sea: species composition, abundance and diversity, Biogeosciences, 5, 1765-1782, 2008, http://www.biogeosciences.net/5/1765/2008/.

Roelke, D. L. and Eldridge, P. M.: Mixing of supersaturated assemblages and the precipitous loss of species, Am. Nat., 171, 162-175, 2008.

Roy, S. and Chattopadhyay, J.: Towards a resolution of "the paradox of the plankton": a brief overview of the proposed mechanisms, Ecol. Complex., 4, 26-33, 2007.

Shurin, J. B., Arnott, S. E., Hillebrand, H., et al.: Diversity-stability relationship varies with latitude in zooplankton, Ecol. Lett., 10, 127-134, 2007.

Walker, S. C. and Cyr, H.: Testing the standard neutral model of biodiversity in lake communities, Oikos, 116, 143-155, 2007.

Weiler, C. S.: Population structure and in situ division rates of Ceratium in oligotrophic waters of the North Pacific central Gyre, Limnol Oceanogr., 25, 610-619, 1980.

Whittaker, R. H.: Evolution and measurement of species diversity, Taxon, 21, 213-251, 1972. 